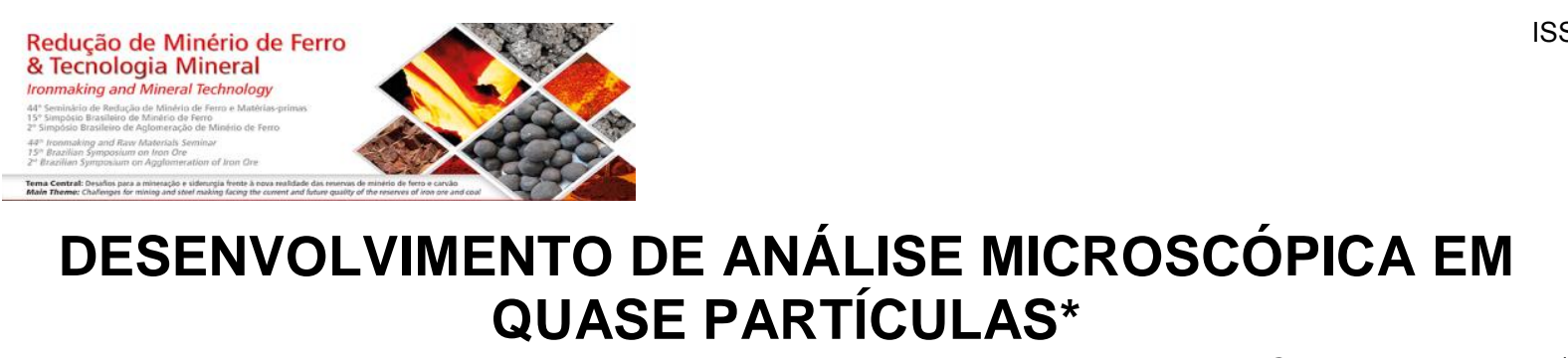

\title{
DESENVOLVIMENTO DE ANÁLISE MICROSCÓPICA EM QUASE PARTÍCULAS*
}

\section{Resumo}

Renata Cristina Alves Elias ${ }^{1}$ Thiago Pinto Silva ${ }^{2}$ José Roberto Magalhães ${ }^{3}$

A análise por microscopia óptica em quase partículas, obtidas após a aglomeração a frio, é de grande importância para o entendimento do processo de sinterização, pois permite determinar aspectos qualitativos e quantitativos da aglomeração, assim como identificar o arranjo microestrutural entre as partículas nucleantes, aderentes, combustíveis e fundentes das misturas a sinterizar. Neste contexto, foi desenvolvida uma metodologia para preparar e analisar ao microscópio amostras da mistura a sinterizar, visando auxiliar na identificação de relações entre as suas características e os parâmetros de produção e de qualidade do sínter. O método desenvolvido permite determinar a porcentagem de quase partículas, de partículas não aglomeradas e de partículas micropelotizadas em cada amostra. Além disso, permite identificar e medir as dimensões do material (minério, sínter, coque, fundente, quartzo) que constitui o núcleo de cada quase partícula e avaliar o material que não aglomera.

Palavras-chave: Quase partículas; Ensaio de granulação; Aglomeração a frio; Análise microscópica.

\section{DEVELOPMENT OF THE MICROSCOPIC ANALYSIS IN QUASI PARTICLES}

\begin{abstract}
The microscopic analysis in quasi particles obtained after cold agglomeration is fundamental for the understanding of sintering process because it allows to determine qualitative and quantitative aspects of agglomeration as well as identify the microstructure arrangement between nucleating, adherent, fuel and fluxes of sintering mixtures. In this context a methodology to prepare and analyze a sinter mix samples under the microscope was developed, aiming to help the identification of relations between their characteristics, production parameters and sinter quality. The developed method allows to identify the percentage of quasi particles, not agglomerated and agglomerated particles. Moreover, it is possible to quantify material dimensions (ore, sinter, coke, flux and quartz) that forms the quasi particle nucleus.
\end{abstract}

Keywords: Quasi particles; Granulation test; Cold agglomeration; Microscopic analysis.

1 Engenheira Química, M.Sc., Pesquisadora, Centro de Tecnologia Usiminas; Ipatinga, MG, Brasil.

2 Membro da ABM; Engenheiro Metalurgista, Pesquisador, Centro de Tecnologia Usiminas; Ipatinga, MG, Brasil.

3 Técnico em Metalurgia, Centro de Tecnologia Usiminas; Ipatinga, MG, Brasil.

* Contribuição técnica ao 44 Seminário de Redução de Minério de Ferro e Matérias-primas, $15^{\circ}$ Simpósio Brasileiro de Minério de Ferro e $2^{\circ}$ Simpósio Brasileiro de Aglomeração de Minério de Ferro, 15 a 18 de setembro de 2014, Belo Horizonte, MG, Brasil. 


\section{INTRODUÇÃO}

A produtividade da planta de sinterização está diretamente ligada a dois parâmetros característicos das misturas: o diâmetro médio da mistura e a permeabilidade do leito. O primeiro, de natureza geométrica, está relacionado à distribuição granulométrica da mistura. O segundo é função da resistência oferecida pelo leito ao fluxo de ar quando a mistura é submetida a uma depressão. Estes fatores são interdependentes e estão diretamente ligados à granulometria e às características aglomerantes das matérias-primas e, ainda, à eficiência dos misturadores.

As quase partículas são agregados obtidos após o processo de aglomeração a frio e devem apresentar resistência adequada. $O$ desenvolvimento de ensaios de caracterização em laboratório para avaliar aspectos qualitativos e quantitativos da aglomeração, assim como identificar o arranjo microestrutural entre as partículas nucleantes, aderentes, combustíveis e fundentes das misturas a sinterizar é muito importante para determinação da melhor configuração dos agregados para a sinterização.

O objetivo desse trabalho é mostrar o desenvolvimento da metodologia para preparar e analisar ao microscópio amostras do ensaio de Granulação [1], utilizado para medir o tamanho médio das quase partículas de uma mistura crua, visando auxiliar na identificação de relações entre o seu comportamento e os parâmetros de produção e qualidade do sínter.

\section{MATERIAIS E MÉTODOS}

Os principais equipamentos necessários para desenvolvimento do ensaio são:

- lixadeira plana;

- bomba de vácuo;

- rebaixadora de lâminas;

- bancada de polimento (25 $\mathrm{mm} \times 30 \mathrm{~mm})$;

- máquina de corte com disco diamantado; e,

- microscópio óptico.

Os materiais utilizados para desenvolvimento do ensaio são:

- resina;

- catalisador;

- vaselina sólida;

- forma de embutimento de 40 mm de diâmetro;

- álcool;

- algodão;

- óleo lubrificante;

- lixas d'água; e,

- luvas cirúrgicas.

\section{RESULTADOS E DISCUSSÃO}

\subsection{Preparação das Amostras}

\subsubsection{Amostragem}

Foram utilizadas amostras aleatórias do ensaio de Granulação, realizado no Laboratório de Aglomeração do Centro de Tecnologia Usiminas. A amostra é constituída por uma mistura de minério, coque, antracito, fundentes (calcário e

* Contribuição técnica ao 44 Seminário de Redução de Minério de Ferro e Matérias-primas, $15^{\circ}$ Simpósio Brasileiro de Minério de Ferro e $2^{\circ}$ Simpósio Brasileiro de Aglomeração de Minério de Ferro, 15 a 18 de setembro de 2014, Belo Horizonte, MG, Brasil. 
dolomita), aglomerante (cal), minério de manganês, pó de alto-forno, rejeito industrial, degradado, carepa e pó da sinterização.

Foram selecionadas três faixas do ensaio de Granulação para serem trabalhadas: partículas maiores que $4,76 \mathrm{~mm}$; entre $4,76 \mathrm{~mm}$ e $2,83 \mathrm{~mm}$; e, partículas entre 2,83 $\mathrm{mm}$ e $1,00 \mathrm{~mm}$.

Primeiramente, as amostras coletadas após o ensaio de Granulação eram transportadas em bandejas para posterior embutimento. Visando evitar ao máximo 0 manuseio do material, optou-se pela coleta das amostras na própria forma de embutimento. As quase partículas devem então ser depositadas na forma utilizando uma espátula e distribuídas de forma que toda a superfície esteja coberta com partículas. Esta montagem é levada para secagem em estufa durante $1 \mathrm{~h}$ a $105^{\circ} \mathrm{C}$.

\subsubsection{Embutimento}

Verificou-se o desempenho de dois tipos de resina: a de cura rápida e de cura lenta. Para embutimento com a resina de cura rápida, foram utilizadas $0,2 \mathrm{ml}$ de catalisador para cada $50 \mathrm{ml}$ de resina. A resina, primeiramente, foi levada à estufa $\left(40^{\circ} \mathrm{C}\right)$ entre $10 \mathrm{~min}$ e $15 \mathrm{~min}$, para elevar sua fluidez. Para embutimento com a resina de cura lenta, a medida foi de $12,5 \mathrm{ml}$ de resina para $1,6 \mathrm{ml}$ do catalisador.

A resina deve ser despejada lentamente, visando evitar a desintegração das quase partículas. Todo cuidado com a sua integridade deve ser tomado.

Após preenchidas com resina, as formas foram levadas à estufa aquecida a $40^{\circ} \mathrm{C}$. A resina de cura lenta permaneceu ali por cerca de $12 \mathrm{~h}$, enquanto que a de cura rápida por cerca de $3 \mathrm{~h}$.

As duas resinas apresentaram embutimentos de boa qualidade. A resina de cura lenta é mais fácil de manusear. Com a resina de cura rápida só é possível preparar uma amostra por vez, pois a fluidez diminui muito rapidamente, dificultando 0 manuseio com o tempo. Na figura 1 são mostrados embutimentos obtidos com a resina de cura lenta.

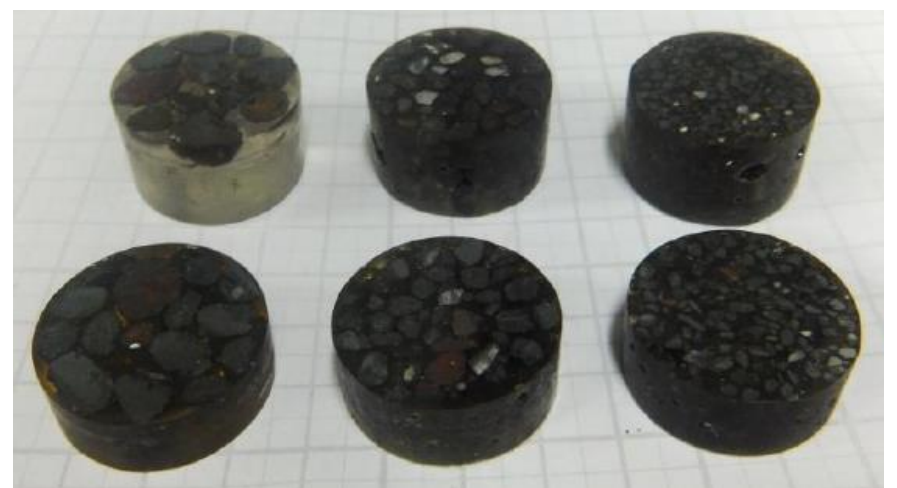

Figura 1. Embutimento das quase partículas.

O uso de ambas as resinas propiciou a formação de poros esféricos no embutimento. Para saná-los ou reduzi-los elevou-se o tempo no vácuo de 5 min para 20 min, usando a resina de cura lenta. Na figura 2 são mostradas fotomicrografias de embutimentos para as duas condições na qual é possível verificar a extinção dos poros. 


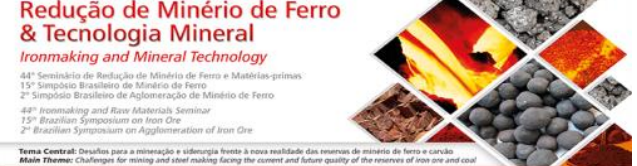

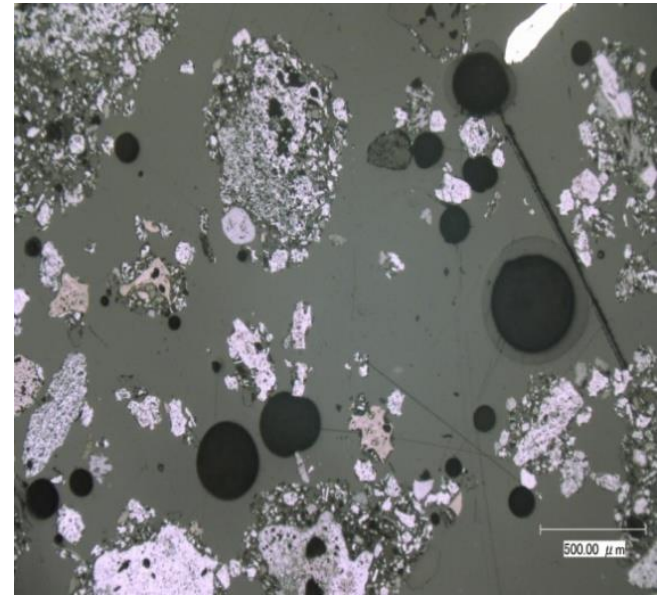

(a) tempo no vácuo de 5 min

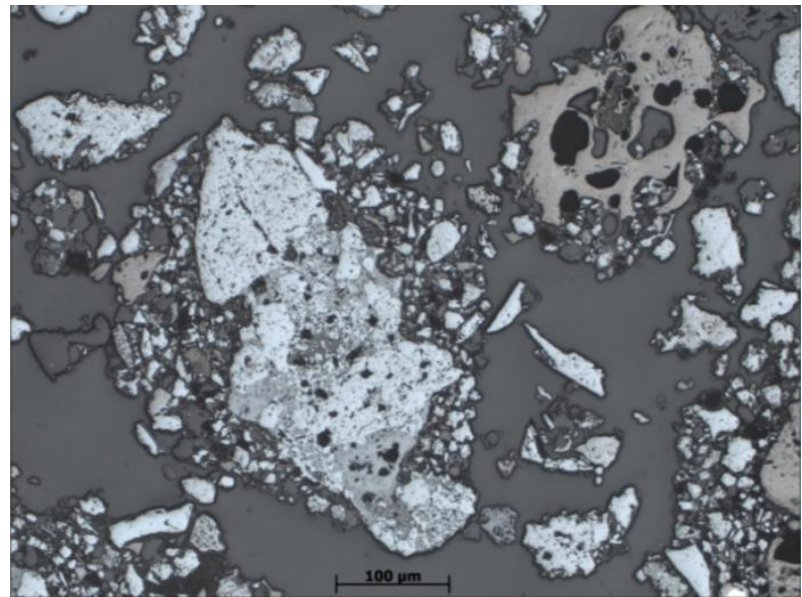

(b) tempo no vácuo de 20 min

Figura 2. Fotomicrografias mostrando poros na resina com alteração do tempo de vácuo.

\subsubsection{Corte}

Essa etapa é fundamental, uma vez que o ensaio consiste em analisar um corte longitudinal na superfície das quase partículas. O embutimento foi levado a uma máquina de corte de precisão. Foi feito um corte padrão para nivelar o fundo do embutimento. Em seguida, o aparelho foi ajustado para realizar um corte fino e preciso através das quase partículas (figura 3). Após o corte, a amostra foi levada à estufa $\left(80^{\circ} \mathrm{C}\right.$ durante $1 \mathrm{~h}$ ) para eliminar a umidade superficial adquirida.

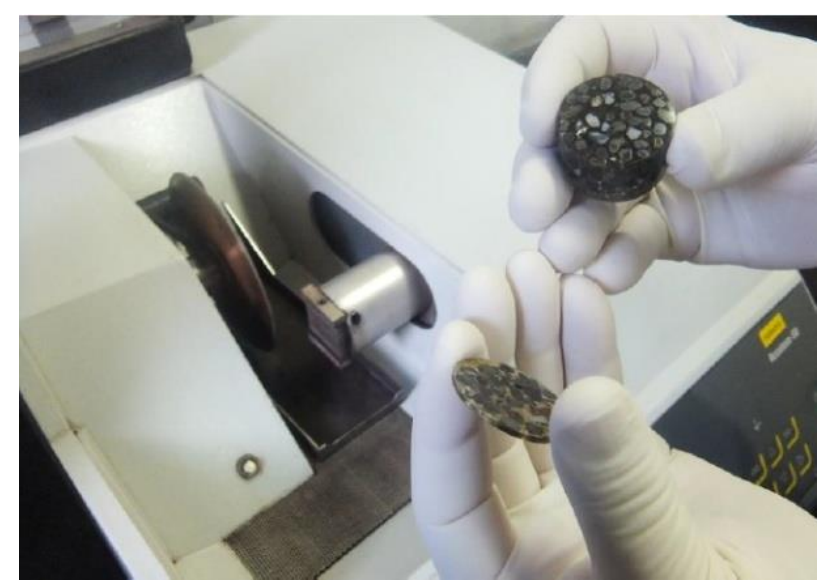

Figura 3. Corte das amostras.

\subsubsection{Impregnação}

Após o corte, a superfície de análise do embutimento foi preenchida com uma fina camada de resina. O objetivo é fazer com que a resina penetre nos poros das quase partículas. Testou-se tanto a resina de cura rápida quanto a de cura lenta, ambas a $40^{\circ} \mathrm{C}$ durante $15 \mathrm{~min}$, e concluiu-se que a última apresentou melhores resultados, por apresentar menos partículas desprendidas, conforme figura 4.

* Contribuição técnica ao 44 Seminário de Redução de Minério de Ferro e Matérias-primas, 15o Simpósio Brasileiro de Minério de Ferro e 2o Simpósio Brasileiro de Aglomeração de Minério de Ferro, 15 a 18 de setembro de 2014, Belo Horizonte, MG, Brasil. 


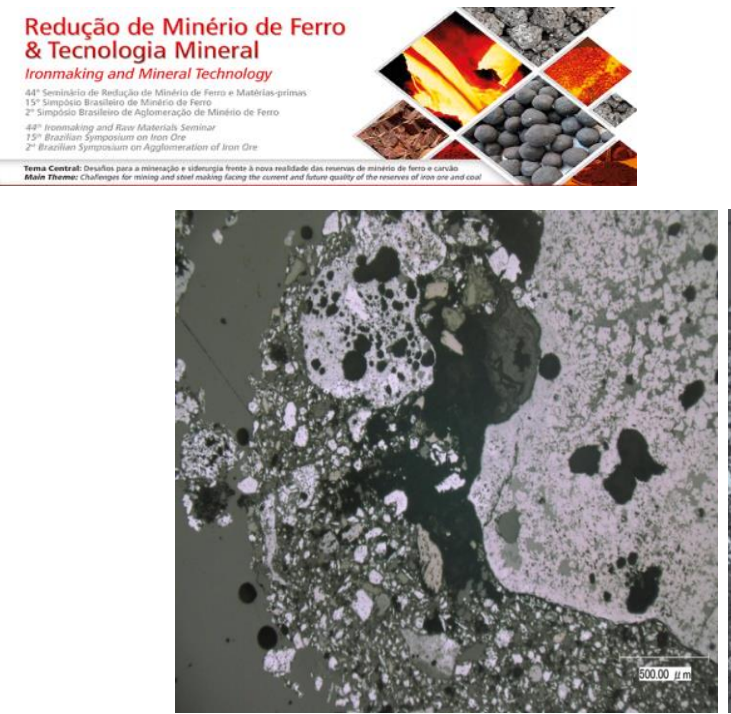

(a) resina de cura rápida

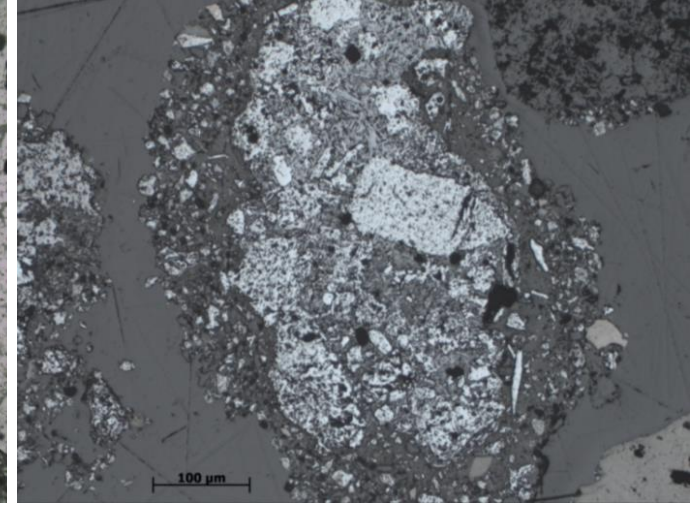

(b) resina de cura lenta

Figura 4. Fotomicrografias mostrando o efeito do tipo de resina na impregnação.

Assim sendo, a impregnação foi realizada com cura lenta, levando-a a estufa $\left(40^{\circ} \mathrm{C}\right.$ durante $15 \mathrm{~min}$ ). Com a camada de resina, o embutimento foi submetido ao vácuo por 5 min. Em seguida, foi levado à estufa por cerca de $1 \mathrm{~h}-2 \mathrm{~h}$ na temperatura de $40^{\circ} \mathrm{C}$ até seu completo endurecimento.

\subsubsection{Lixamento}

As amostras foram lixadas na seguinte sequência de lixas de grão: 320 \#, 600 \#, 800 \# e 1200 \# (figura 5). Deve-se atentar para a execução de lavagens em água corrente e secagem com $\mathrm{N}_{2}$ entre uma lixa e outra. Materiais processados com a presença de cal ou de calcário tendem a apresentar resquícios de cal livre que, durante o lixamento, podem reagir com água. Assim, é possível que o desprendimento de calor dessa reação comprometa a qualidade do embutimento final. Como solução para essa situação, pode-se substituir a água por óleo lubrificante.

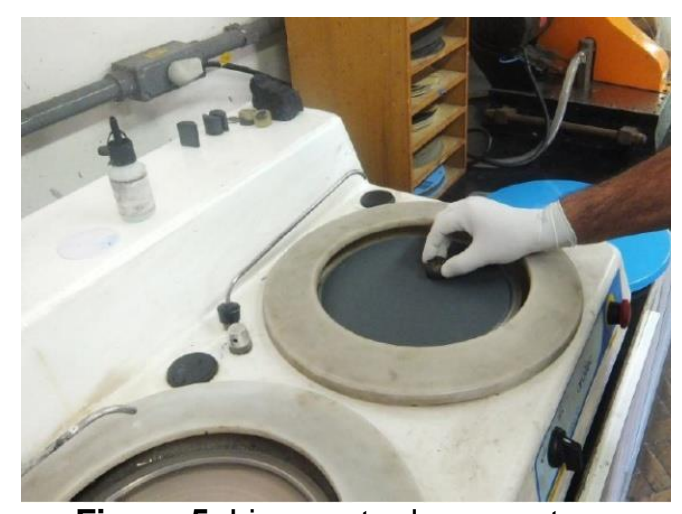

Figura 5. Lixamento das amostras.

\subsubsection{Polimento}

Com as quase partículas embutidas e impregnadas, o procedimento de polimento é semelhante ao de sínteres e minérios, que utiliza politriz automática com os seguintes parâmetros de força, tempo e rotação: $10 \mathrm{~N}-60 \mathrm{~N}, 10 \mathrm{~min}$ e $40 \mathrm{rpm}$, respectivamente. Após o término do polimento final as amostras foram lavadas em água corrente e secas com $\mathrm{N}_{2}$.

\subsection{Análise Microscópica}

Para identificação e contagem das partículas separadas por faixas granulométricas foram obtidos mosaicos de cada amostra embutida com resina de cura lenta,

* Contribuição técnica ao 44 Seminário de Redução de Minério de Ferro e Matérias-primas, $15^{\circ}$ Simpósio Brasileiro de Minério de Ferro e 2o Simpósio Brasileiro de Aglomeração de Minério de Ferro, 15 a 18 de setembro de 2014, Belo Horizonte, MG, Brasil. 
utilizando um microscópio óptico com luz polarizada e objetiva de $5 x$, conforme figura 6. A classificação utilizada para quantificação das partículas foi:

- quase partícula (núcleo): aglomerado com mais de uma camada de fração aderente em torno de um núcleo definido, figura 7 (a);

- partícula não aglomerada: partícula com nenhuma ou uma fina camada de fração aderente em torno de um núcleo definido, figura 7 (b); e,

- micropelotizada: partícula aglomerada com materiais finos, sem núcleo definido, figura 7 (c).

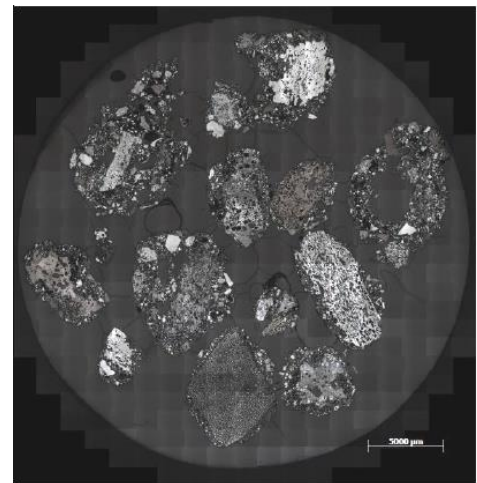

(a) $>4,76 \mathrm{~mm}$

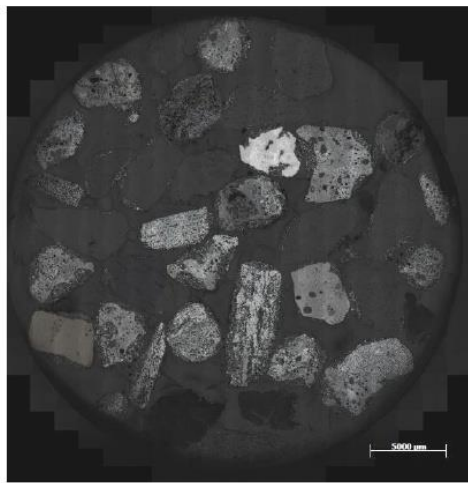

(b) 2,83 $\mathrm{mm} \sim 4,76 \mathrm{~mm}$

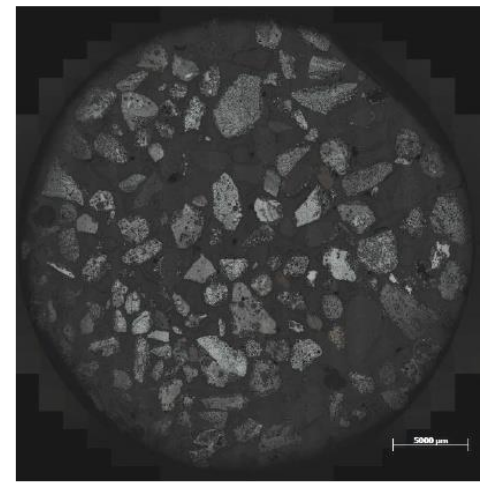

(c) $1,00 \mathrm{~mm} \sim 2,83 \mathrm{~mm}$

Figura 6. Mosaicos obtidos de cada amostra embutida (50X).

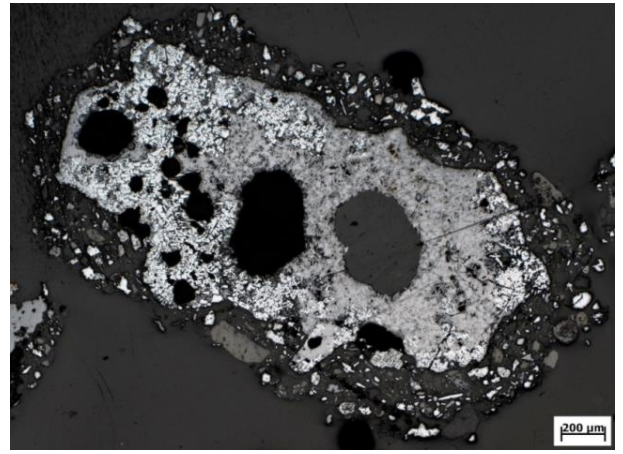

(a) quase partícula

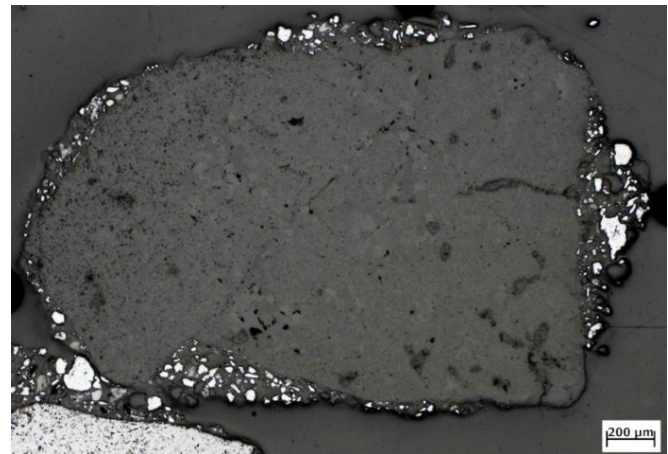

(b) partícula não aglomerada

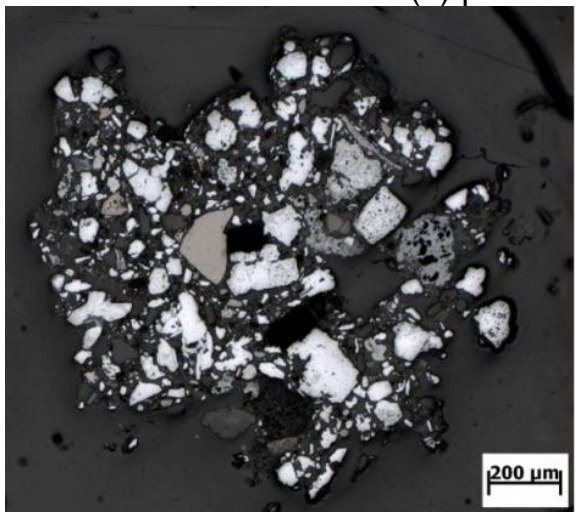

(c) partícula micropelotizada

Figura 7. Classificação das partículas (50X) (continuação).

Para todas as classificações de partículas, deve ser anotada a quantidade total identificada no mosaico. As partículas identificadas como núcleo da quase partícula e partícula não aglomerada devem ser classificadas em tipos, quais sejam: sínter, carvão, coque, antracito, fundentes, hematita (tabular, granular, lobular e martita), goethita, quartzo, magnetita e outros. Após a coleta de dados deve-se preencher a

* Contribuição técnica ao $44^{\circ}$ Seminário de Redução de Minério de Ferro e Matérias-primas, 15은 Simpósio Brasileiro de Minério de Ferro e $2^{\circ}$ Simpósio Brasileiro de Aglomeração de Minério de Ferro, 15 a 18 de setembro de 2014, Belo Horizonte, MG, Brasil. 
planilha de resultados, conforme apresentado na figura 8. Como resultados serão obtidos:

- porcentagem de quase partículas, partículas não aglomeradas e micropelotizadas em relação à amostra global;

- porcentagem de cada constituinte identificado nas quase partículas e partículas não aglomeradas em relação à quantidade das mesmas; e,

- porcentagem de hematita tabular, granular, lobular e martita em relação à quantidade total de hematita identificada.

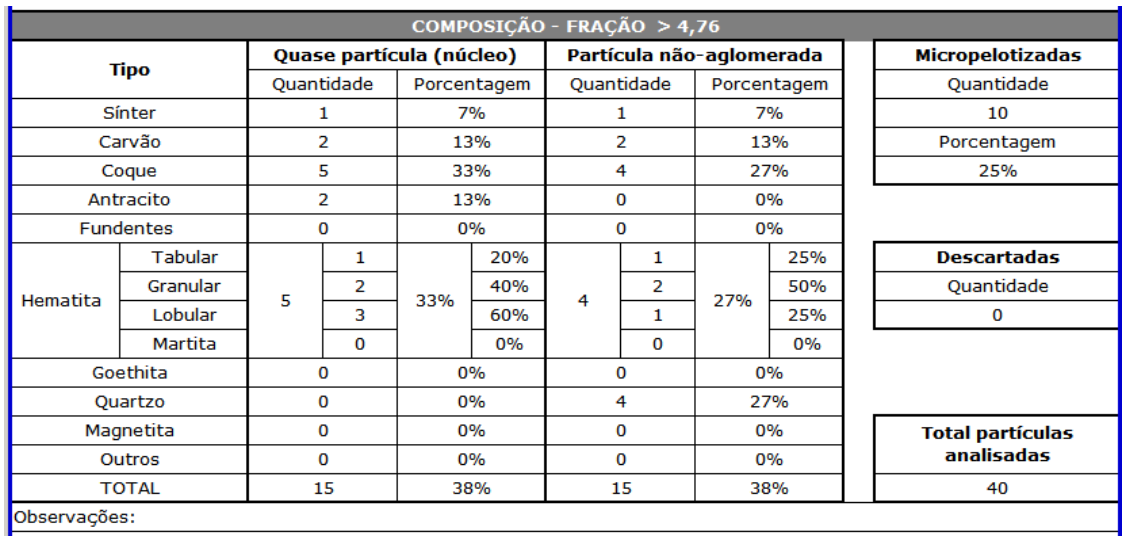

Figura 8. Planilha de resultados (exemplo).

\section{CONCLUSÃO}

Foi desenvolvida metodologia para preparação e análise ao microscópio de amostras de quase partículas obtidas do ensaio de Granulação.

As amostras devem ser manuseadas o mínimo possível. Por isto optou-se pela coleta direta do material no local de realização do ensaio, utilizando a forma de embutimento.

Notou-se que tanto a resina de cura rápida quanto a de cura lenta apresentaram embutimentos de boa qualidade. Porém, como com a resina de cura rápida só é possível preparar uma amostra por vez, optou-se pela utilização da resina de cura lenta por ser mais fácil de manusear.

$O$ analista deve avaliar criteriosamente a diferença entre as quase partículas e as partículas não aglomeradas.

Esta metodologia possibilita avaliar qualitativamente e quantitativamente as partículas nucleantes para o caso de quase partícula, posicionamento do combustível e dos fundentes nos agregados, medir a eficiência da formação de agregados, entre outros. Entre as diversas possibilidades de análises, essas informações associadas a outras permitem auxiliar, por exemplo, na determinação da configuração mais adequada dos agregados para a sinterização.

\section{Agradecimentos}

Os autores agradecem à equipe de pesquisadores da Nippon Steel \& Sumitomo Metal Corporation pelo apoio durante o desenvolvimento da metodologia.

\section{REFERÊNCIAS}

1 Furui T, Kawazu M, Sugawara K, Fujiwara T, Kagawa M, Sawamura A, Uno S. Seitetsu Kenkyu. 1976; n. 288, 9, apud Hosotani Y, Konno N, Yamaguchi K, Orimoto T, Inazumi T. Reduction properties of sinter with fine dispersed pores at high temperatures of $1273 \mathrm{~K}$ and above. ISIJ International. 1996; 36: 1439-1447.

* Contribuição técnica ao $44^{\circ}$ Seminário de Redução de Minério de Ferro e Matérias-primas, 15은 Simpósio Brasileiro de Minério de Ferro e $2^{\circ}$ Simpósio Brasileiro de Aglomeração de Minério de Ferro, 15 a 18 de setembro de 2014, Belo Horizonte, MG, Brasil. 